ARTICLE HISTORY: Received: August: 6, 2021 Accepted: September 27, 2021 Published: October 4, 2021

УПРАВЛЕНИЕ ЭНЕРГОСБЕРЕЖЕНИЕМ В ГАЗОДОБЫВАЮЩИХ КОМПАНИЯХ

Рябов Валерий Сергеевич

студент магистратуры кафедры «Экономика и управление»

Тихоокеанского государственного университета

2. Хабаровск, Тихоокеанский государственный университет

\title{
ENERGY SAVING MANAGEMENT IN GAS PRODUCTION COMPANIES
}

\author{
Ryabov Valery Sergeevich \\ Master's student of the Department of Economics and Management, \\ Pacific State University \\ Khabarovsk, Pacific State University
}

\begin{abstract}
Аннотация. В данной статье изложены проблемы энергосбережения на промышленных предприятиях, предложен системный подход к управлению энергосбережением в газодобывающих компаниях и выделены его главные подсистемы, рекомендовано использование комплексной оценки деятельности предприятия в области энергосбережения.

Abstract. This article outlines the problems of energy conservation at industrial enterprises, proposes a systematic approach to energy conservation management in gas producing companies and highlights its main subsystems, recommends the use of a comprehensive assessment of the enterprise's activities in the field of energy conservation.

Ключевые слова: энергосбережение, системный подход, подсистемы управления, комплексная оценка.

Key words: energy saving, system approach, control subsystems, complex assessment.

Достижение одного из главных стратегических ориентиров долгосрочной государственной энергетической политики, а именно энергетической эффективности экономики, во многом зависит от деятельности предприятий и компаний в области энергосбережения. В соответствии с концепцией энергосбережения и повышения энергетической эффективности на 2011-2021 гг. основной задачей ПАО «Газпром» является максимальная реализация потенциала энергосбережения во всех видах деятельности и совершенствование управления энергосбережением.

В последнее время большое внимание уделяется теоретическим и практическим аспектам управления энергосбережением. Несмотря на это, для многих промышленных предприятиях проблема энергосбережения остается актуальной по определенным объективным и субъективным причинам, в том числе несовершенство системы планирования и контроля энергосбережения, отсутствие систем мотивации достижения результатов в области энергосбережения, отсутствие специальных структур управления энергосбережением, недостаточная обоснованность управленческих решений в рассматриваемой области и другие [1]. Все это приводит к тому, что деятельность предприятий, направленная на повышение энергоэффективности часто ограничивается реализацией комплекса разрозненных мероприятий, сдерживает возможности реализации потенциала энергосбережения и, как следствие, получение устойчивых результатов в долгосрочной перспективе. Поэтому автором предлагается именно системный подход к управлению энергосбережением, предполагающий осуществление непрерывного и циклического процесса реализации процедур в рамках выделенных подсистем. Состав подсистем определяется на основе анализа и обобщения опыта применения циклических моделей в области повышения энергоэффективности, в том числе представленных в ISO 50001:2012 [2]. К данным подсистемам управления относятся: целеполагание, реализация, контроль и регулирование (рис. 1).
\end{abstract}




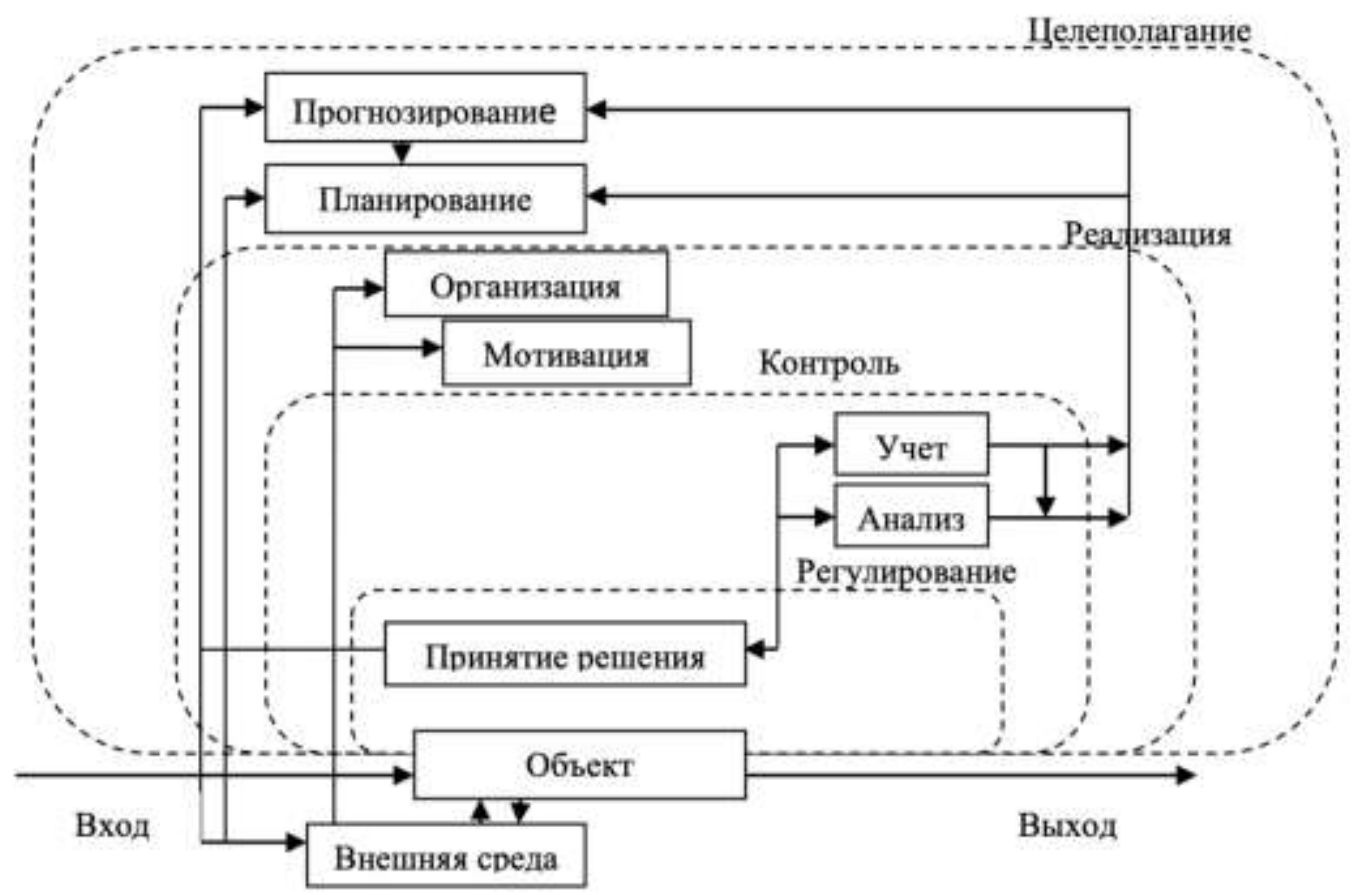

Рис.1. Системный подход к управлению энергосбережением

Предполагается набор действий в пределах определенных функций управления для реализации каждой из указанных подсистем (таблица 1).

Таблица 1

\begin{tabular}{|c|c|c|}
\hline $\begin{array}{l}\text { Подсистем } \\
\mathrm{a} \\
\end{array}$ & $\begin{array}{c}\text { Функции } \\
\text { управления }\end{array}$ & Действия \\
\hline \multirow{2}{*}{$\begin{array}{l}\text { Целеполаг } \\
\text { ание }\end{array}$} & $\begin{array}{l}\text { Прогнозиров } \\
\text { ание }\end{array}$ & $\begin{array}{l}\text { Комплексная оценка деятельности предприятия в } \\
\text { энергосбережения, бенчмаркинг энергосбережения, внешний } \\
\text { энергоаудит, выявление тенденций изменения показателей } \\
\text { энергосбережения, установление целевых ориентиров и определение } \\
\text { направлений деятельности предприятия в области энергосбережения. }\end{array}$ \\
\hline & $\begin{array}{c}\text { Планировани } \\
\text { e }\end{array}$ & 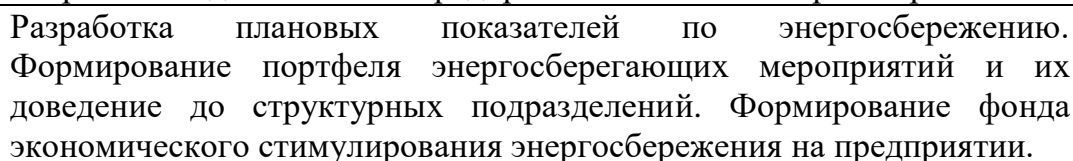 \\
\hline
\end{tabular}

Реализация системного подхода управления энергосбережением начитается с комплексной оценки деятельности предприятия в рассматриваемой области. Предлагаемый подход к осуществлению комплексной оценки деятельности газодобывающего предприятия в области энергосбережения в отличие от существующих позволяет учесть специфику отрасли, оценить производственные и управленческие аспекты энергосбережения по четырем основным направлениям: 1) организационное, 2) экономическое, 3) социально-психологическое, 4) производственное. Каждое из направлений учитывает состояние системы нормирования потребления энергоресурсов, их коммерческого и технического учета, отчетности; ведение технической документации в части энергохозяйства; состояние системы коммуникаций по вопросам энергосбережения и другие. Экономическое направление позволяет оценить инвестиционную политику предприятия в рассматриваемой области, состояние системы стимулирования энергосбережения. Социально-психологическое направление предполагает, оценку системы подготовки и переподготовки персонала в области энергосбережения. Производственное направление отражает фактическое использование энергоресурсов по их видам (природный газ, электроэнергия, теплоэнергия).

Показатель комплексной оценки оценивается балльным методом. Элементы 1-3 оцениваются по установленному перечню характеристик, для каждой из которых экспертным путем определяется максимально возможное значение. При рассмотрении производственного направления оценка осуществляется с учетом значимости энергосбережения каждого вида ресурса. 
Конечным результатом комплексной оценки деятельности предприятия в области энергосбережения является выявление отклонений фактических значений частных показателей по каждому направлению от максимально возможных. Это создает информационную базу для разработки плановых показателей по энергосбережению и формирования комплекса энергосберегающих мероприятий.

Таким образом, применение системного подхода к управлению энергосбережением позволяет упорядочить данный процесс, создать объективную основу для принятия эффективных управленческих решений и повысить уровень энергоэффективности предприятий.

\section{СПИСОК ЛИТЕРАТУРЫ}

1. Оценка деятельности предприятия в области энергосбережения / Л. Н. Руднева [и др.] // Известия высших учебных заведений. Социология. Экономика. Политика. - 2012. - No 2. - С. 46-50.

2. Национальный стандарт Российской Федерации системы энергетического менеджмента: ГОСТ ИСО 50001-2012 [Электронный ресурс]. - Режим доступа http://docs.cntd.ru/document/gost-r-iso-50001-2012

\section{References}

1. Evaluation of the enterprise's activity in the field of energy saving / LN Rudneva [et al.] // News of higher educational institutions. Sociology. Economy. Politics. - 2012. - No 2. - S. 46-50.

2. National standard of the Russian Federation of the energy management system: GOST ISO 50001-2012 [Electronic resource]. - Access mode http://docs.cntd.ru/document/gost-r-iso-50001-2012 